ISAHP 1999, Kobe, Japan, August 12-14,1999

\title{
CHOOSING THE OPTIMAL MARKETING MIX FOR SCHOOL MILK USING EXPERT CHOICE, A MANAGEMENT DECISION SUPPORT SYSTEM
}

\author{
Walter Schiebel and Konrad Hackl \\ Institute of Agricultural Economics (Agricultural Marketing Group) \\ University of Agricultural Sciences, Vienna \\ Peter Jordan Straße 82, A-1190 Vienna \\ Phone $+431476543560,3561$ \\ Fax +431476543562 \\ E-mail: schiebel@edv1.boku.ac.at
}

\begin{abstract}
Short abstract
The Analytic Hierarchy Process (AHP approach) can be applied to poorly-defined marketing-mix problems, but the technique has received little attention in the Germanspeaking literature. The hierarchical expression of decision-making processes with due consideration to complementarity allows us to better understand and visualise interdependencies between marketing instruments.
\end{abstract}

\begin{abstract}
The business and its defined goals and objectives are normally the first point of reference when considering the marketing mix. In this context, however, the objective of the business should be seen as maximum customer utility rather than return on equity.

Conjoint analysis is the most common method used for market segmentation and for designing new products, evaluating product plans and determining prices. A condition of the technique is that the attributes tested should be independent of one another. This condition is, however, not satisfied in the marketing mix case. Conjoint analysis is often based on a linear-compensatory model, which carries the implication that the perceived utility associated with a particular expression of a characteristic is not influenced by the values or expressions of other characteristics. This is particularly problematic when prices and brands are considered, since these two factors are often correlated.

As a school milk study shows, the problem cannot be resolved by splitting it into a series of discrete, comparable parts, since it is made up of a number of component problems at different levels; direct comparisons between problems at these different levels are not possible. Put another way, a component problem can only be compared with other problems at the same level, and then evaluated according to its individual importance.

The Analytic Hierarchy Process (AHP approach) can be applied to poorly-defined marketing-mix problems, but the technique has received little attention in the German-speaking literature. The independence requirement for the characteristics used is not such an issue in AHP, since groups are created at each hierarchical level. In practice, however, it is not always possible to avoid some kind of interaction between elements (characteristics) within a group. The aim, however, is to construct groups such that interdependence between elements within the group is minimised.

The hierarchical expression of decision-making processes with due consideration to complementarity allows us to better understand and visualise interdependencies between marketing instruments. When planning the marketing mix, AHP takes account of those non-time related quantitative and (to a lesser extent) qualitative aspects which are able to contribute in isolation or combination to the achievement of relevant objectives.

AHP is a particularly valuable tool for determining the optimal marketing mix, but not just because it can be used for evaluating a set of alternatives. AHP also provides a framework for those activities that must
\end{abstract}


precede such an evaluation, namely description and structuring of the decision-making problem and process.

AHP appears frequently in the Anglo-American literature; over 1500 English-language documents dealing. with basic AHP issues and applications are listed at the internet addresses http://www.expertchoice.com/hierarchon/references/reflist.htm

and

http://www.expertchoice.com/hierarchon/references/disslist.htm. Although there is currently much less familiarity with AHP elsewhere in the world, the technique is set to grow in importance in the Germanspeaking world.

In the field study presented here, the clear consensus of opinion among decision-makers driving the school milk programme was that the market acceptance of the programme is too low and a range of serious changes need to be made if the programme is to survive into the future. Research undertaken in the past shows that the overlying objective is "the establishment of a successful school milk programme". The well-known criticisms of this programme can be used to define appropriate (sub-)objectives. The main objective can only be reached through the fulfilment of these sub-objectives, namely an increase in the security of supply, increased sales, increased attractiveness of the programme/products, reduction in labour requirements and improved nutrition.

Decision-makers - parents, teachers, school heads and janitors - were surveyed in order to be able to identify preferences. Data entry, pair comparisons and the analysis were carried out using the software package Expert Choice 9.0.

In summary, the results showed that the objective "establish a successful school milk programme" can be best achieved by concentrating efforts on the following sub-objectives; increase attractiveness, reduction in labour requirements and improved nutrition.

\section{Full Paper}

\section{Introduction and objectives}

In the last five years, there has been an unprecedented collapse in the Austrian school milk market. A range of factors have combined to make school milk relatively unattractive and cause consumption to decline. Particular problems include a reduction in support, logistical difficulties with supply and distribution of milk to (and within) schools, the increasingly poor image of milk among children and teenagers, changes in eating habits, outmoded packaging, and ineffective advertising. Most of these problems are not, however, intrinsically insurmountable. The real problem lies in the milk marketing mix. The study presented here was limited to primary schools in Vienna, given time constraints and the organisational problems which would have been associated with broader coverage. The relevant consumer group is, therefore, between 6 and 10 years of age. The research client also specified that the study focused on this target age group. The study draws on pre-existing market data, analyses and research, all of which relate to these particular consumers (insofar as such material exists for these ages). Decision-makers (parents, teachers, school heads and janitors) were also surveyed in order to be able to identify preferences. Bureaucratic difficulties precluded a survey of the children themselves. However, children's needs and ideas were taken into account by drawing on the range of comprehensive research which has already been carried out on children on this topic.

The main question addressed in the study is: What marketing mix for school milk is best able to meet the requirements of parents and primary schools. Interesting secondary questions are: What do children expect from a school milk drink (answered using a review of existing research and literature)? Who decides whether a school milk programme is introduced, or whether a school/children participate in an existing programme (i.e. identification of the decision-makers)? How are school milk programmes organised and what problems are caused by the existing organisational structure? Can UHT milk-based drinks help solve some of the problems?

The principal aim of the study, therefore, is to find the marketing mix which is best able to satisfy the needs of the customers (the primary schools) under existing circumstances. 


\section{UHT milk-based products for (school)children}

In the last few months there has already been a move toward expanding UHT milk-based product ranges in Austria. Maresi recently introduced three products for children under the brand name Sigi. One product is an iced tea, the other two are based on UHT milk with $3.5 \%$ fat content (cocoa-flavoured and nougatflavoured). These products are being positioned as premium goods, not just through their price (ATS 9.9 for $200 \mathrm{ml}$ at Billa/REWE supermarket), but also through the novel packaging and a massive TV advertising campaign. According to management, Maresi have no intention of using these products in the school milk programme, since the prices (which are fixed by the government) are too low to support a branded product.

Toward the end of 1997, Alpenmilch Salzburg Ges.m.b.H. introduced a new school milk product under the name "Alex, der Piratendrink" (Alex, the pirates' drink). This is a chocolate milkshake-type drink made from UHT milk, with $1.5 \%$ fat content and added vitamins and glucose. According to sales management, the product launch was very successful. Average monthly sales of $250 \mathrm{ml}$ units across the first four months of 1998 were ca. 45,000 in schools and ca. 55,000 through the retail grocery trade. The success within the school milk programme is of particular interest, since it not only involved schools and children switching from fresh milk to UHT milk, but also a change from two-way glass packaging to oneway packaging. These changes were accepted without comment by decision-makers and schoolchildren. However, no reduction in delivery frequencies proved possible, because fresh milk products were still being delivered concurrently.

Milupa has recently entered the market with the Milupino Kindermilch UHT milk drink (vanillaflavoured and banana-flavoured) and a strawberry-yoghurt drink. The milk drinks have a fat content of $3.5 \%$ and are enriched with calcium, iron, iodine, 10 vitamins and vegetable oils. A pack of three $200 \mathrm{ml}$ units costs between ATS 16.9 and ATS 19.9, depending on the retail outlet. According to the packaging, the drinks are intended for toddlers and children up to primary school age. However, the product is probably not perceived very favourably by six to ten year olds, since the packaging is very babyish (a teddy bear riding a scooter).

\section{School milk in Austria}

There is a clear consensus of opinion among decision-makers (as defined earlier) that the market acceptance of the school milk programme is too low and a range of serious changes need to be made if the programme is to survive into the future. A majority of parents and teachers do see snacks between meals as useful and are demanding that there be more of them. Decision-makers believe that milk should play a key role in child nutrition, even though our understanding of milk is far from complete. The results of research undertaken in the past can be used to define an overlying objective, namely "the establishment of a successful school milk programme". There are five main criticisms of the existing school milk programme; inadequate security of supply, inadequate sales, an unattractive programme/product, excessive labour requirements and deficiencies in terms of nutrition. These criticisms can be converted into appropriate (sub-)objectives which need to be addressed if the main objective is to be achieved. These sub-objectives are an improvement in the security of supply, increased sales, increased attractiveness of the programme, reduction in labour requirements and improved nutrition. They are described in more detail below, from the perspective of the decision-makers:

Improvement in the security of supply (punctual delivery, proper completion of orders in terms of volume and type of products delivered, competent contact partners in the delivery firms and dairies, solution of the perishability problem),

Increase in sales (increased sales means an increase in compensation for the effort invested. At the moment, the dairies pay a sales commission of ATS 0.25 for each $250 \mathrm{ml}$ unit),

Increase in attractiveness of the product (more diverse product range and modern products),

Reduction in labour requirements (for those working in supply, storage and distribution, and for those responsible for distributing the milk in the schools themselves),

Improved nutrition (supply of calcium and vitamins). 
This study evaluated the individual importance of each sub-objective and their weighting in terms of contributing to the achievement of the overall objective. The results identify those sub-objectives whose pursuit should be emphasised in order to achieve the overall goal of "establishing a successful school milk programme". Various marketing mix instruments are available for achieving these sub-objectives, and these are presented below. The labels used in the decision-making hierarchy (see Expert Choice structuring) are given in brackets.

Product policy (Product): Product policy is a useful marketing instrument for all of the sub-objectives mentioned. Three potential alternatives were defined and presented to the decision-maker; the conventional products already found in school milk programmes (milk and cocoa) and the new, UHT milk based drinks suggested by the client (five different flavours; three fruit flavours, nougat and cocoa). This particular instrument also covers packaging design, branding and product name.

Price policy (Price): This instrument is not included in the evaluation of the sub-objectives "increase security of supply" and "reduction in labour requirements", since it has no influence on them. The legislative framework is the decisive factor here. In general, UHT milk products are ATS 0.5 cheaper than normal milk products with the same fat content.

Distribution policy (Supply and Distribution): This instrument is of key relevance to all sub-objectives. Two expressions of this instrument were more closely defined and presented to the decision-maker; supply interval (Supply), where the choice was daily, twice a week and once a week (only possible with UHT milk products), and frequency with which children can select products (Distribution), where the alternatives were a free, daily choice (only possible with UHT milk products, since the children also have the option of choosing no product), weekly selection of school milk products and monthly selection of school milk products. Punctuality of delivery and proper completion of orders (volume and product type) were also included under this instrument.

Communication policy (Advertising): This instrument cannot contribute to the achievement of the subobjectives "increase security of supply" and "reduction in labour requirements", and was not considered in these two cases. Communication policy includes various kinds of promotional and informational events, visits to dairies, competitions, further education on nutritional issues for both teachers and children (using specialist advisors), provision of information in the form of teaching materials, free tastings and advertising (of the school milk programme).

\section{The research process}

As described earlier, the study focused on primary schools in Vienna and involved a survey of parents, teachers, school heads and janitors. One of the key purposes of the research was to identify the importance of the different potential marketing measures through an understanding of preferences for particular alternatives. Data entry, pair comparisons and the analysis were carried out using the software package Expert Choice 9.0. This software also allows the user to create a model - a decision-making hierarchy - using the "structuring" module. Elements and levels within this model can be organised or restructured very quickly, so that the representation of relationships is as realistic and genuine as possible. The software then turns the model so created into a hierarchy for evaluation by decision-makers. The usefulness of this hierarchy is first evaluated in a pre-test. The software is extremely flexible, so any ideas, comments or improvements suggested by a decision-maker can easily be incorporated into the hierarchy as new elements or levels. In the same way, elements or levels which are seen as irrelevant to the decision-making process can be removed.

An initial pre-test was carried out with an expert in marketing and the milk economy. As a result, the subobjective "cost minimisation" was removed from the hierarchy, since this objective relates to the dairy industry and is not an issue of relevance to parents or other decision-makers in the school. The model was otherwise seen as a sufficiently true and comprehensive representation of the most important factors driving the "successful school milk programme" decision-making process. A second pre-test with a primary school teacher revealed problems with specialist marketing terms. It was clear that some of these 
terms would not be understood (or would be misinterpreted) by laypersons. There was a particular problem with the terms "distribution policy" and "communication policy". This potential problem was solved by using the words "supply and distribution" instead of "distribution policy", and the word "advertising" in place of "communication policy". The term "policy" itself caused confusion in the context of prices and products. Price and product policy were therefore simply described as "price" and "product". In order to ensure that respondents shared a common level of understanding, each was given the same, comprehensive briefing on instruments used in the marketing mix before taking the survey. A final pre-test was carried out with a parent representative. They found the proposed hierarchy to be a true reflection of reality and had no problem with the terms used, indicating that the model was ready for practical application.

The survey was carried out using a 486 laptop with $24 \mathrm{Mb}$ RAM. The colour screen made it easier for respondents to complete the evaluation, since Expert Choice 9.0 uses coloured elements (input and output boxes) to improve clarity and user-friendliness. Hierarchical elements change colour, for example, once they have been evaluated, thus helping to ensure that no elements go unevaluated. The researcher undertook the actual input of responses, so that the expert respondents could concentrate on the actual evaluation. The questions asked in the context of the pair comparisons appeared on the computer screen (mostly in English due to the origin of the programme), but were also read out loud to the respondent by the researcher

Examples of the type of questions used for each hierarchical level are: (First level) Which sub-objective do you think is the most important with regard to the main objective of establishing a successful school milk programme - a reduction in labour requirement or an improvement in the attractiveness of the programme/products? Which sub-objective has to play the biggest role in establishing a successful school milk programme - (for example) an improvement in security of supply or an increase in the attractiveness of the programme/products? (Second level) In your opinion, which marketing instrument is more important with regard to achieving the sub-objective of (for example) improving the security of supply product policy (product) or distribution policy (supply and distribution)? (Third level) Which is more likely to improve sales - cocoa or a milk-based drink? Which supply interval (or selection interval) is most likely to lead to an increase in the attractiveness of the programme? (Fourth level) At this level, respondents were asked to decide whether UHT milk or fresh milk should be preferred (or would be more appropriate) in the context of the foregoing levels or objectives. Of course, certain combinations of answers precluded a choice at this stage. The programme always checks for consistency after each set of evaluations. Once the survey is completed, the programme also checks whether all questions have been answered and automatically saves a copy of the responses to disk. Any relevant comments made by decision-makers before, during and after the evaluation process were recorded and used in analysing and interpreting the results.

It was clear from the pre-tests that the survey itself would last around 1 hour 15 minutes, and potential respondents were informed of this when agreeing appointments over the telephone. As a result, three contacts were unable to participate in the survey because of time constraints. All participating experts found the survey very interesting, both because of the topics covered and because of the way in which the survey was carried out. This probably explains why the results were very consistent and why none of the interviews were cut short, despite the length of the survey.

The respondent sample consisted of 1 . five parent representatives (the chairperson of the national umbrella organisation for Parent Associations; the chairperson of the Vienna Parent Association; the former chairperson of the Vienna Parent Association and current chairperson of a primary school parent association in Vienna; two parents with children attending primary school), 2. four primary school teachers who had made some efforts on behalf of a school milk programme, 3. three primary school heads and 4. three janitors. These decision-makers were contacted and questioned on a somewhat informal basis, since an official survey would have required special permission from the Vienna schools authority (which would not necessarily have been forthcoming and which would have taken several months to organise).

Time and organisational constraints meant that the research was unable to draw on group discussions. The survey should have been completed within weeks 25 and 26 , during preparations for the end of the school year. It was only possible to complete the survey because respondents were given total autonomy in terms 
of the time and date of interviews. As a consequence, some interviews were even carried out in the first two weeks of the summer break.

Each hierarchy was analysed in isolation and the resultant weightings put into an Excel table. Individual evaluations were aggregated using averages and a new hierarchy produced.

\section{Results}

The results were presented to the client for each hierarchical level and element, in terms of ranked preferences. The complete hierarchy, including the weightings for each element, are given in our poster (for a sample decision-maker). This should help people find their way around the hierarchy and make it easier to understand the analysis. In summary, decision-makers found that UHT milk was much better suited to achieving and maintaining a secure supply of products and a reduction in labour requirements. Fresh milk was, however, clearly preferred in terms of improving nutrition and increasing the attractiveness of the programme. UHT milk was given a slight advantage in terms of increasing sales. This gives the marketing planner a clearer understanding of the pros and cons associated with each product type, and the results can be used as the basis for determining the optimal marketing mix (according to Expert Choice).

\section{References}

AgrarMarkt Austria (1998): Marktbericht für Milch und Milchprodukte, Wien

Mitteregger, M. (1996): Wettbewerbssituation und Marktchancen - eine Portfolioanalyse für den österreichischen Haltbarmilchmarkt. Wien: Diplomarbeit. Universität für Bodenkultur Wien.

Ossadnik, W. (1998): Mehrzielorientiertes strategisches Controlling. Methodische Grundlagen und Fallstudien zum fuhrungsunterstutzenden Einsatz des Analytischen Hierarchie-Prozesses. Heidelberg: Physica-Verlag.

Platt, A. and Schiebel, W. (1993): Der Analytische Hierarchieprozeß als Gestaltungsmethode zur Lösung schlecht-strukturierter, komplexer Probleme im logistischen Bereich. In: Schiebel, W. (Ed): Forschungsbericht Logistik, Institut für Absatzwirtschaft, WU Wien, Selbstverlag.

Saaty, Th. L. (1995): Decision Making for Leaders, The Analytical Hierarchy Process for Decisions in a Complex World. Pittsburgh: RWS Publications.

Schiebel, W. (1986): Neue erklärungs- und entscheidungsorientierte Ansätze zum Buying-CenterKonzept. In: Theuer et al.: Beschaffung - ein Schwerpunkt der Unternehmensfuhrung. Landsberg, Lech: Verlag Moderne Industrie. $195-219$.

Schiebel, W.; Hohenecker, J. and Spitzer M. (1996): Zur Aripassung der österreichischen Milchwirtschaft an den EU-Milchmarkt - Ergebnisse einer Delphi-Studie. dmz, Volume 6, 292 - 298.

Tscheulin, D. K. (1991): Ein empirischer Vergleich der Eignung von Conjoint-Analyse und "Analytic Hierarchy Process" (AHP) zur. Neuproduktgestaltung. ZfB, Zeitschrift für Betriebswirtschaft, Sonderdruck, Verlag Gabler, Nr. 11, 1267 - 1280.

Weber, K. (1993): Mehrkriterielle Entscheidungen. Munchen, Wien: Oldenbourg. 